\title{
Study of Deprotection Reaction during Exposure in Chemically Amplified Resists for Lithography Simulation
}

\author{
Yasuhiro Miyake, Mariko Isono and Atsushi Sekiguchi \\ Litho Tech Japan Corporation, 2-6-6-201, Namiki, Kawaguchi, Saitama 332-0034, Japan
}

\begin{abstract}
Deprotection reactions of chemically amplified resists during exposure are observed by using the in-situ FT-IR with the 248nm light source, and resist profiles are simulated using the activation energy and the prefactor calculated. The resists used in this experiment are poly(p-hydroxystyrene) (PHS) protected by Ethoxyethyl (EOE) group, by tert-Butoxycarbonyl (t-BOC) group and by these heterogeneous protection groups. The activation energy for the EOE resist is much lower than that for the $\mathrm{t}$-BOC resist. The existence of heterogeneous protection groups affect mutually deprotection reactions; the EOE group additions to $t-B O C$ resist reduce the activation energy for the deprotection reaction of $t-B O C$ group. It is confirmed that existences of heterogeneous protection groups affect the formation of resist pattern profile by lithography simulator.
\end{abstract}

Keywords: deprotection reaction, CA resist, activation energy, simulation

\section{INTRODUCTION}

Beginning with the study by Ito et al. in $1987^{[1]}$, chemically amplified (CA) resists using acid catalyzed reactions have become indispensable for manufacturing sub-half micron semiconductor devices. During this period, various studies have been performed to improve the resolution of CA resists and to improve environmental stability ${ }^{[2]-[5]}$. In positive-type CA resists, acid is produced by catalysis in photochemical reactions, and protection groups are dissociated in the heating process (PEB: post exposure bake) that follows exposure. Therefore the acid generation efficiency, the acid diffusion, the type of protection groups and the protection ratios are closely related to $C A$ resist performance. Clearing of deprotection reactions is essential for the development of resists and the evaluation of process. In recent years, appropriate models for deprotection reactions during PEB have been proposed ${ }^{[6]-[8]}$. However there have been few reports of analysis of deprotection reactions during exposure $^{[9]}$. Therefore we use an FT-IR spectrometer equipped with a UV light source, analyze and model of deprotection reactions during exposure in positive-type CA resists. In addition to determining the parameters for lithography simulation, we simulate the resist profiles.

\section{EXPERIMENTAL}

The analysis system used in this experiment was the MODEL PAGA-100 by Litho Tech Japan (Fig. 1).

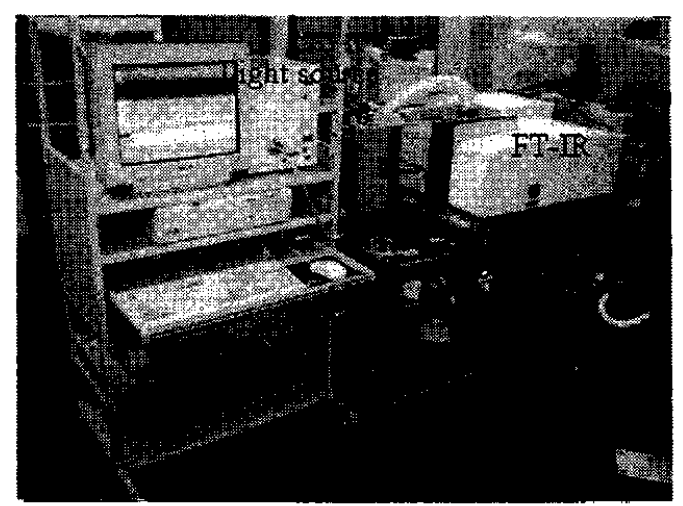

Fig. 1 External view of the MODEL PAGA-100

This system was based on a standard FT-IR spectrometer, but equipped with a light source, a bake plate and a wafer transport shuttle in the sample chamber (Fig. 2). The exposure light used a dielectric film filter to narrow the spectral bandwidth to $248 \mathrm{~nm}$ from a VU-rays of Xe-Hg lamp. Exposure power in wafer surface was 3 $\mathrm{mW} / \mathrm{cm}^{2}$. 


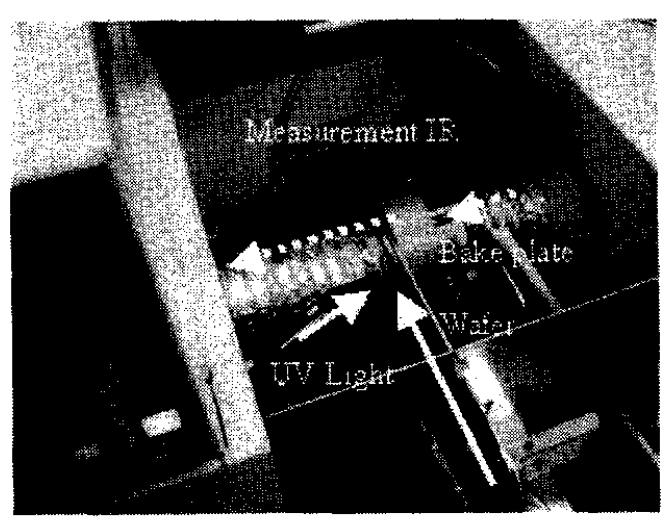

Fig. 2 Internal view of the MODEL PAGA-100 sample camber

The bake plate was used to control the ambient temperature during exposure from room temperature to $150{ }^{\circ} \mathrm{C}$. In order to enable in-situ observations of IR-rays through a $\mathrm{Si}$ wafer, a 10 $\mathrm{mm}$ diameter hole was punched in the center of the bake plate. In measurement, at first a sample was inserted into the sample chamber by a wafer transport shuttle, started exposure and measurement as soon as sample reached the set temperature by the bake plate.

The resists used in this experiment were composed of PHS protected by EOE group or by t-BOC group, and by these heterogeneous protection groups (Fig. 3). Table 1 shows the resists composition.

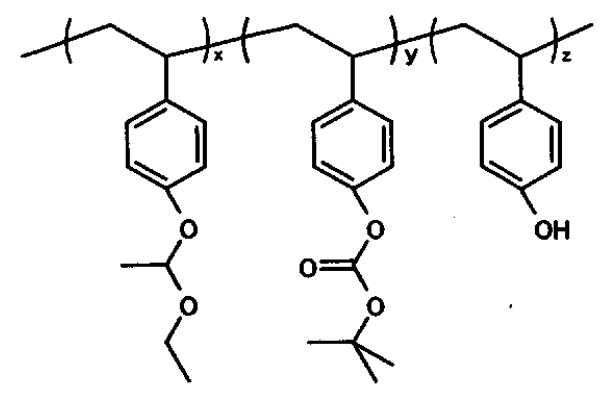

PAG: $\mathrm{Ph}_{3} \mathrm{~S}^{+}-\mathrm{OSO}_{2} \mathrm{CF}_{3}$ (3wt\%)

Fig. 3 Resist structure

Table 1 Resists composition

\begin{tabular}{|c|c|c|c|}
\hline & EOE(x) & t-BOC(y) & OH(z) \\
\hline H450055 & $45 \%$ & $0 \%$ & $55 \%$ \\
\hline $\mathrm{C} 260965$ & $26 \%$ & $9 \%$ & $65 \%$ \\
\hline $\mathrm{C} 122365$ & $12 \%$ & $23 \%$ & $65 \%$ \\
\hline $\mathrm{H} 003565$ & $0 \%$ & $35 \%$ & $65 \%$ \\
\hline
\end{tabular}

The homopolymer resist used was PHS protected by $45 \%$ EOE group, (named H450055, numbers are the protection percentage of $\mathrm{EOE}, \mathrm{t}-\mathrm{BOC}$, and $\mathrm{OH}$ group), or by $35 \% \mathrm{t}-\mathrm{BOC}$ group (H003565). The copolymer resist used was PHS protected by $26 \%$ EOE group and by $9 \%$ t-BOC group
(C260965), or protected by $12 \%$ EOE group and by $23 \%$ t-BOC group (C122365). Triphenyl sulphonium triflate was used at $3 \mathrm{wt} \%$ into the resists as a photo acid generator (PAG).

The resists were spin-coated at $1 \mu \mathrm{m}$ thickness on $\mathrm{Si}$ wafer for all samples, and were prebaked at $90{ }^{\circ} \mathrm{C}$ for $90 \mathrm{~s}$. These samples were exposed in the sample chamber during exposure varied, and in-situ measurements of the IR spectra were performed. The decreases of characteristic absorption obtained from in-situ measurements were converted to deprotection reaction curves. The deprotection reaction curves were fitted by exponential functions as the deprotection reaction constant $C_{2}\left[\mathrm{~cm}^{2} / \mathrm{mJ}\right]$. The activation energy $E_{a}$ $[\mathrm{kJ} / \mathrm{mol}]$ and the prefactor $\ln \left(\mathrm{A}_{\mathrm{r}}\right)\left[\mathrm{s}^{-1}\right]$ were calculated from an Arrhenius plot of $C_{2}$, and compared. A sequence of analyses was calculated by the Deprotection Simulator software ${ }^{[8,9]}$.

The other parameters for lithography simulations were determined by the development rate measurement system RDA-790 and the ABC parameter analyzer MODEL- $400^{[10]}$.

\section{Deprotection Reaction Model}

The EOE resist generates the acid by exposure. The acid is amplified by heat reaction of PEB. It causes the deprotection reaction of EOE group. The dissociated EOE group undergoes hydrolysis and decomposes to ethanol and aldehyde (Fig. 4a) ${ }^{[11]}$. The t-BOC resist generates the acid by exposure. The acid is amplified by heat reaction of PEB. It causes the deprotection reaction of $\mathrm{t}-\mathrm{BOC}$ group. The dissociated $t-B O C$ group decomposes to carbon dioxide and isobutene (Fig. 4b) ${ }^{[1,12]}$.

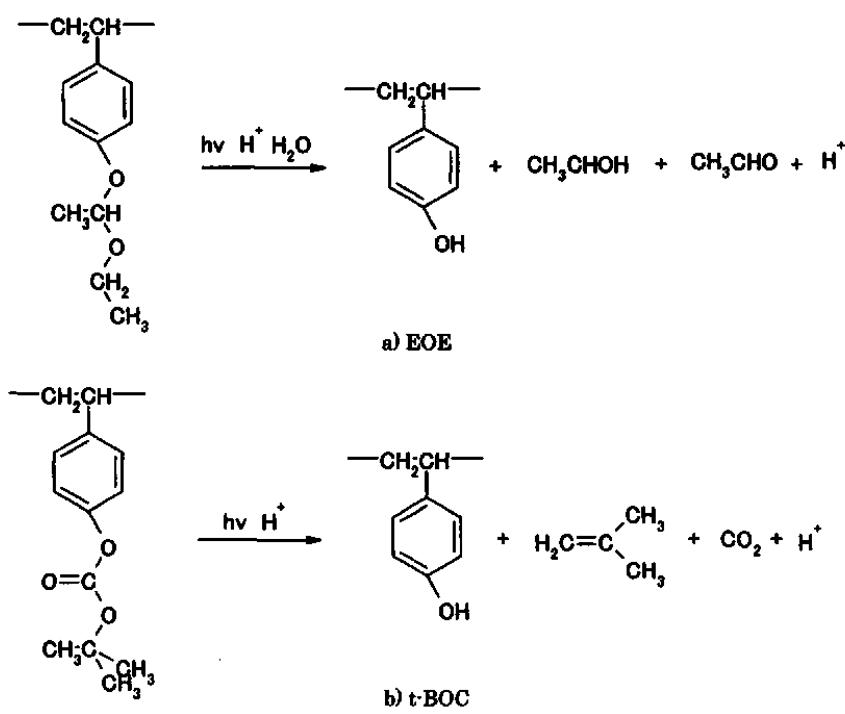

Fig. 4 Deprotection reaction mechanism 


\section{RESULTS}

\subsection{Measurement Results}

Fig. 5 shows C260965 in-situ IR spectra from deprotection during exposure of $\mathrm{EOE}$ group and t-BOC group at $68^{\circ} \mathrm{C}$.

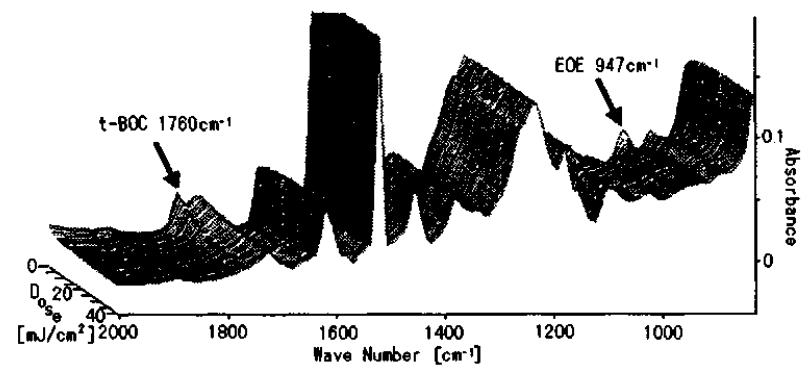

Fig. 5 IR absorption spectra of $\mathrm{C} 260965$ at $68^{\circ} \mathrm{C}$

As the exposure dose increased, characteristic absorption of ether groups at $947 \mathrm{~cm}^{-1}$ decreased in the EOE group, and of ester carbonyl groups at $1760 \mathrm{~cm}^{-1}$ decreased in the $\mathrm{t}-\mathrm{BOC}$ group. The characteristic absorption was standardized as protection ratio.

Fig. 6 shows protection ratio of PHS versus exposure dose.

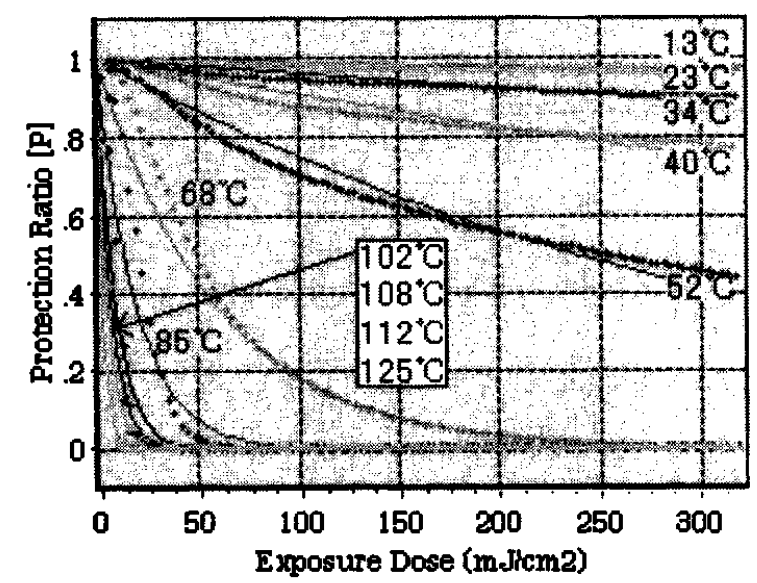

Fig. 6 Protection ratio vs. exposure dose for t-BOC group

Deprotection reaction occurred with increase in the exposure ambient temperature, and an exponential function was fitted to the deprotection reaction curve (Eq. 1).

$$
[P]_{\exp }=\exp \left(-C_{2} E\right)
$$

where $[\mathrm{P}]_{\exp }$ is the protection ratio, $\mathrm{C}_{2}$ is the deprotection reaction constant, and $\mathrm{E}$ is the exposure dose.

Fig. 7 shows Arrhenius plots of deprotection reaction constant $\mathrm{C}_{2}$, calculated from Eq. 1 for the several samples with the exposure ambient temperature varied.

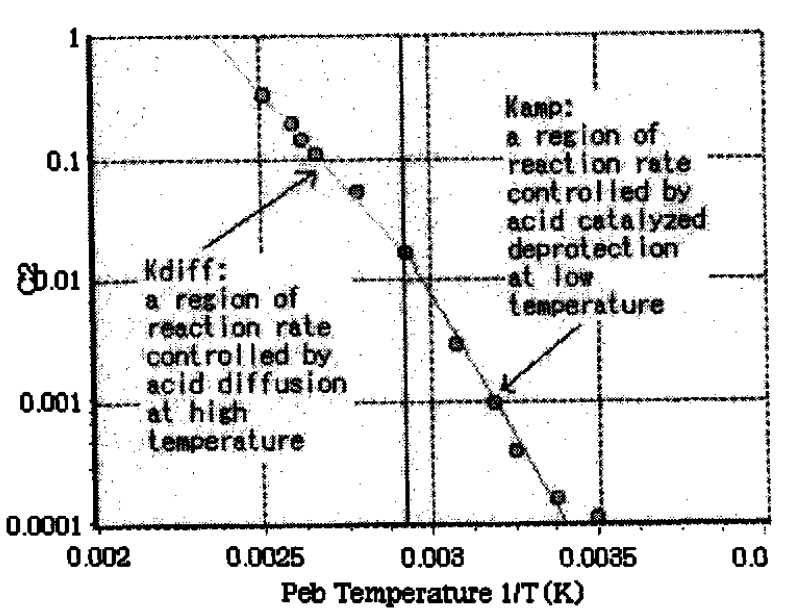

Fig. 7 Arrhenius plot of deprotection reaction constant $C_{2}$ for t-BOC group

Eq. 2 shows the Arrhenius formula.

$$
C_{2}=A_{r} \exp \left(-E_{a} / R T\right)
$$

where $\mathrm{C}_{2}$ is the deprotection reaction constant, $A_{r}$ is the prefactor, $E_{a}$ is the activation energy, $R$ is the universal gas constant, and $\mathrm{T}$ is the absolute temperature.

Existence of different two regions was found by the activation energies calculated from Arrhenius plots; a region of reaction rate controlled by acid catalyzed deprotection at low temperature ( $\mathrm{K}_{\mathrm{amp}}$ ), a region of reaction rate controlled by acid diffusion at high temperature $\left(\mathrm{K}_{\text {diff }}\right)$. The existence of two regions in the activation energy agreed with the model proposed by Byers and Petersen et al. ${ }^{[13}$, 14].

Fig. 8 shows protection ratio versus exposure dose for EOE group at $23^{\circ} \mathrm{C}$.

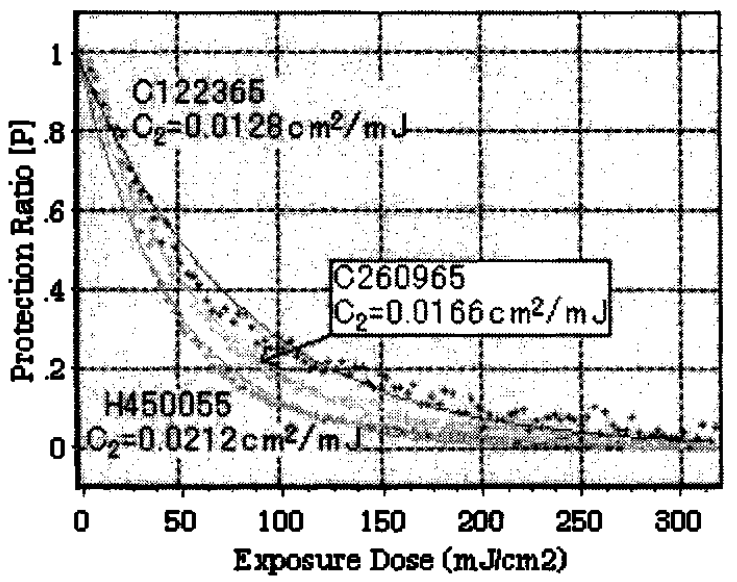

Fig. 8 Protection ratio vs. exposure dose for EOE group at $23{ }^{\circ} \mathrm{C}$ 
Deprotection reaction curves of EOE group became smooth by introducing t-BOC group. Fig. 9 shows protection ratio versus exposure dose for $t-B O C$ group at $68^{\circ} \mathrm{C}$.

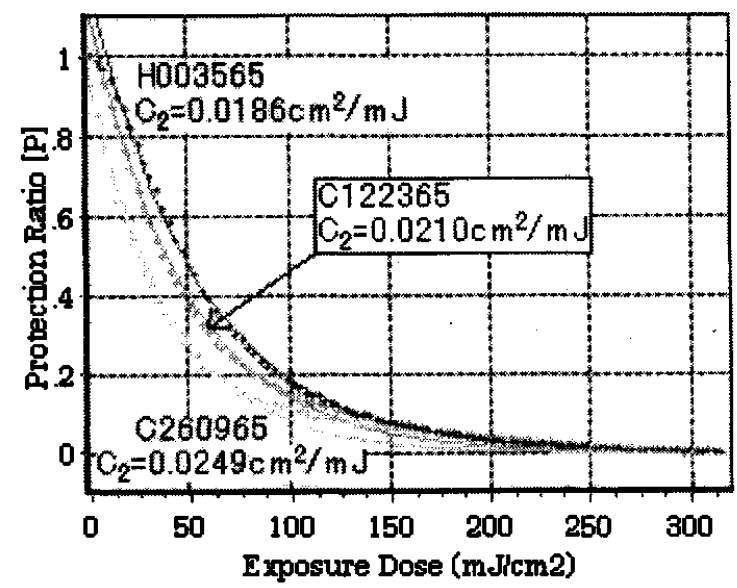

Fig. 9 Protection ratio vs. exposure dose for t-BOC group at $68^{\circ} \mathrm{C}$

Deprotection reaction curves of t-BOC group became sharp by introducing EOE group. It was found that existence of heterogeneous protection groups affected the action of acid on deprotection reaction.

Table 2 shows the activation energies $E_{a}$ and the prefactors $\ln \left(A_{r}\right)$.

Table 2 Activation energies and prefactors

\begin{tabular}{|c|c|c|c|c|c|}
\hline & & H450055 & C260965 & C122365 & H003565 \\
\hline \multirow{4}{*}{ EOE } & $\begin{array}{c}\mathrm{K}_{\text {amp }} \mathrm{E}_{\mathbf{a}} \\
{[\mathrm{kJ} / \mathrm{mol}]}\end{array}$ & 37.24 & 43.09 & 45.44 & - \\
\hline & $\overrightarrow{\mathrm{K}}_{\mathrm{mmp}} \ln \left(\mathrm{A}_{\mathrm{r}}\right)$ & 11.26 & 13.34 & 14.06 & - \\
\hline & $\begin{array}{c}\mathrm{K}_{\mathrm{diff}} \mathrm{E}_{\mathrm{a}} \\
{[\mathrm{kJ} / \mathrm{mol}]}\end{array}$ & 10.38 & 15.77 & 18.03 & - \\
\hline & $\begin{array}{c}\mathrm{K}_{\mathrm{diff}} \ln \left(\mathrm{A}_{\mathrm{r}}\right) \\
{\left[\mathrm{s}^{-1}\right]}\end{array}$ & 1.10 & 3.07 & 3.76 & - \\
\hline \multirow{4}{*}{$t-B O C$} & $\begin{array}{c}\mathrm{K}_{\mathrm{emp}} \mathrm{E}_{\mathrm{a}} \\
{[\mathrm{kJ} / \mathrm{mol}]}\end{array}$ & - & 51.46 & 67.24 & 98.95 \\
\hline & $\begin{array}{c}\mathrm{K}_{\text {amp }} \ln \left(\mathrm{A}_{\mathrm{r}}\right) \\
{\left[\mathrm{s}^{-1}\right]}\end{array}$ & - & 14.31 & 19.53 & 30.80 \\
\hline & $\begin{array}{c}\mathbf{K}_{\text {diff }} \mathrm{E}_{\mathrm{a}} \\
{[\mathrm{kJ} / \mathrm{mol}]}\end{array}$ & - & 28.12 & 34.69 & 44.14 \\
\hline & $\mathrm{K}_{\text {diff }} \ln \left(\mathrm{A}_{\mathrm{r}}\right)$ & - & 6.72 & 8.69 & 11.94 \\
\hline
\end{tabular}

The activation energies were compared at low temperature region. The activation energy for $\mathrm{EOE}$ group deprotection reaction $\left(\mathrm{K}_{\mathrm{amp}} \mathrm{E}_{\mathrm{a}}\right.$ of $\left.\mathrm{H} 450055\right)$ was $37.24 \mathrm{~kJ} / \mathrm{mol}$, while for $\mathrm{t}-\mathrm{BOC}$ group deprotection reaction $\left(\mathrm{K}_{\mathrm{amp}} \mathrm{E}_{\mathrm{a}}\right.$ of $\left.\mathrm{H} 003565\right)$ was $98.95 \mathrm{~kJ} / \mathrm{mol}$. The activation energy for EOE resist was much lower than that for t-BOC resist. Progress of the deprotection reaction in EOE resist during exposure at room temperature could be explained in terms of difference in activation energies. In the copolymer resist, introduction of EOE group into
PHS protected by t-BOC group resulted in decrease of the activation energy required for the $t-B O C$ group deprotection reaction. It was found that existence of heterogeneous protection groups affected the action of acid on deprotection reaction, too.

\subsection{Simulation Results}

Table 3 shows the used parameters in simulations. Resist profiles were simulated with the exposure ambient temperature varied using the activation energies and the prefactors shown in section 3.2 (Figs. 10 and 11).

Table 3 used parameters in simulations

\begin{tabular}{|c|c|}
\hline Parameters & Values \\
\hline Resist Thickness & $700 \mathrm{~nm}$ \\
\hline Prebake & $90{ }^{\circ} \mathrm{C} / 90 \mathrm{~s}$ \\
\hline A & $-0.03 \mu \mathrm{m}^{-1}$ \\
\hline B & $0.24 \mu \mathrm{m}^{-1}$ \\
\hline $\mathrm{C}$ & $0.04 \mathrm{~cm}^{2} / \mathrm{mJ}$ \\
\hline Development Time & $60 \mathrm{~s}$ \\
\hline Development Model & Mack \\
\hline Development $\mathbf{R}_{\max }$ & $308 \mathrm{~nm} / \mathrm{s}$ \\
\hline Development $\mathbf{R}_{\min }$ & $0.11 \mathrm{~nm} / \mathrm{s}$ \\
\hline Development $\mathbf{M}_{\mathrm{th}}$ & 0.01 \\
\hline Development $\mathrm{n}$ & 8 \\
\hline Exposure Wavelength & $248 \mathrm{~nm}$ \\
\hline Feature Width & $250 \mathrm{~nm} \mathrm{~L} / \mathrm{S}$ \\
\hline \multicolumn{2}{|c}{}
\end{tabular}
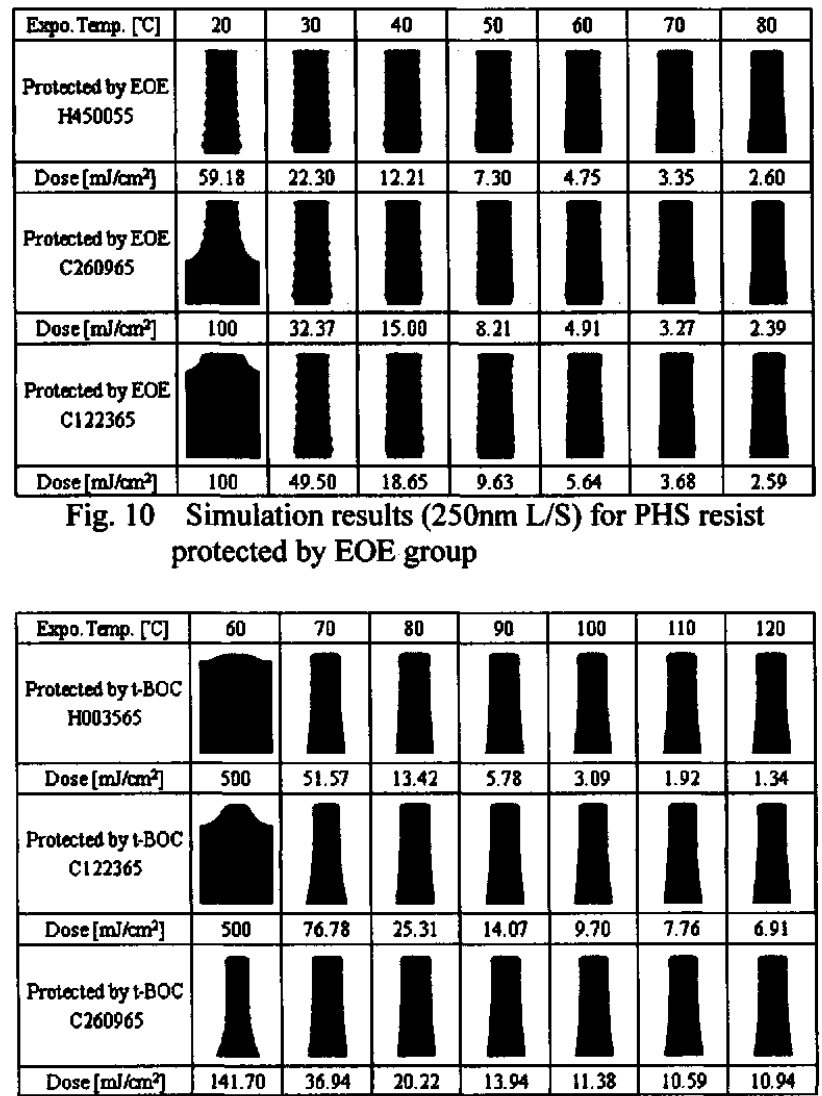

Fig. 11 Simulation results $(250 \mathrm{~nm} \mathrm{L/S)}$ for PHS resist protected by $\mathrm{t}-\mathrm{BOC}$ group 
The simulations were performed focusing on the activation energies and the prefactors for each protection groups. In the case of the PHS protected by EOE group, $250 \mathrm{~nm} \mathrm{~L} / \mathrm{S}$ were patterned at an exposure ambient temperature of $20^{\circ} \mathrm{C}$. However, as the activation energy and the prefactor were increased by introduction of t-BOC group, the optimum exposure dose and the exposure ambient temperature increased. In the case of the PHS protected by t-BOC group, $250 \mathrm{~nm} \mathrm{L/S} \mathrm{were}$ patterned at an exposure ambient temperature of $70{ }^{\circ} \mathrm{C}$. However, the activation energy and the prefactor were increased by introduction of EOE group, with the result that the optimum exposure dose and the exposure ambient temperature were decreased.

It was confirmed that existence of heterogeneous protection groups affected the formation of resist pattern profile.

\section{CONCLUSION}

Until now, the deprotection reaction is observed by sift of characteristic absorption during PEB. However, it is difficult to accurately analyze deprotection reactions at the protection groups like EOE group dissociated at room temperature. But by using this system for the in-situ analysis of deprotection reactions during exposure with the exposure ambient temperature varied, it is possible to obtain valuable insights for deprotection reactions in resists having protection groups which undergo deprotection at room temperatures. In order to clarify change in resist profiles by deprotection reactions during exposure, lithography simulation studies which take into consideration the activation energies of heterogeneous protection groups will be needed.

\section{REFERENCES}

[1] H. Ito and C. G. Wilson, ASC Symp. Ser. 2, (1984), 11.

[2] J. V. Crivello and J. H. W. Lam, Macromolecules, 10, (1977), 1307.

[3] R. A. Ferguson, C. A. Spence, E. Reichmanis, L. F. Thompson and A. R. Neureuther, Proc. SPIE, 1262, (1990), 412.

[4] G. Pawlowski, R. Dammel and C. R. Lindley, Proc. SPIE, 1925, (1993), 213.

[5] R. D. Allen, I. Y. Wan, G. M. Wallraff, R. A. Dipietro and D. C. Hofer, J. Photopolym. Sci. Tecnol., 8, (1995), 623.

[6] T. Ohfuji, A. G. Timko, O. Nalamasu and D. R. Stone, Proc. SPIE, 1925, (1993), 213.

[7] T. Ohfuji, K. Nakano, K. Maeda and E. Hasegawa, $J$. Vac. Sci. Technol., 13, (1995), 3022.

[8] A. Sekiguchi, C. A. Mack, M. Isono and T. Matsuzawa, Proc. SPIE, 3678, (1999), 985.

[9] A. Sekiguchi, Y. Miyake and M. Isono, Jpn. J. Appl. Phys., 39, (2000), 1392.

[10] A. Sekiguchi, C. A. Mack, Y. Minami and T. Matsuzawa, Proc. SPIE, 2725, (1996), 49.

[11] C. Mertesdorf, N. Munzel, H. Holzwarth, P. Falcigno, H. Schacht, O. Rohde and R. Schulz, Proc. SPIE, 2438, (1995), 84.

[12]H. Ito and C. G. Wilson, Polym. Eng. Sci., 23, (1983), 1012.

[13]J. S. Petersen, C. A. Mack, J. W. Thackeray, R. Sinta, T. H. Fedynyshyn, J. M. Mori, J. D. Byers and D. A. Miller, Proc. SPIE, 2438, (1995), 153.

[14] J. S. Petersen, C. A. Mack, J. Sturtevant, J. D. Byers and D. A. Miller, Proc. SPIE, 2438, (1995), 167. 